\title{
In situ high-energy X-ray diffraction of precipitation and dissolution reactions during heating of Al alloys
}

\author{
Hannes Fröck ${ }^{1}$ (D), Christian Rowolt ${ }^{1}$ (1), Benjamin Milkereit ${ }^{1,2, *}$ (D), Michael Reich ${ }^{1}$ (D), \\ Wolfgang Kowalski ${ }^{1}$, Andreas Stark ${ }^{3}$ (D), and Olaf Kessler ${ }^{1,2}$ (D) \\ ${ }^{1}$ Chair of Materials Science, University of Rostock, Rostock, Germany \\ ${ }^{2}$ Department Life, Light and Matter, Competence Centre ${ }^{\circ} \mathrm{CALOR}$, University of Rostock, Rostock, Germany \\ ${ }^{3}$ Institute of Materials Research, Helmholtz-Zentrum Geesthacht, Geesthacht, Germany
}

Received: 5 May 2021

Accepted: 19 September 2021

Published online:

1 October 2021

(C) The Author(s) 2021

\begin{abstract}
During heating of $\mathrm{Al}$ alloys, typically a sequence of precipitation and dissolution reactions occurs and the single (partly opposing) reactions superimpose. Differential scanning calorimetry (DSC) is one common technique to analyse the kinetic development of precipitation and dissolution in $\mathrm{Al}$ alloys, but the superposition of the exothermic precipitation and endothermic dissolution reactions complicates the DSC signal interpretation, as DSC measures the sum of any heat effect. Synchrotron high-energy X-ray diffraction (HEXRD) allows the kinetic development of phase transformations to be obtained and can support the separation of superimposed DSC signals. HEXRD results from this work offer a new approach to separate part of the superimposed reactions and their kinetic development for the equilibrium phases $\beta-\mathrm{Mg}_{2} \mathrm{Si}$ in EN AW-6082 and $\eta-\mathrm{Mg}(\mathrm{Zn}, \mathrm{Cu}, \mathrm{Al})_{2}$ in EN AW-7150. Comparing DSC and HEXRD results confirms serious overlap issues. Common DSC evaluation methods alone, using zero crossing between endothermic and exothermic heat flow or peak positions can be misleading regarding individual reaction start and finish temperatures as well as regarding reaction intensities, which can be unambiguously determined by in situ HEXRD.
\end{abstract}

\section{Introduction}

The kinetic investigation of phase transformations during heating of aluminium alloys is of importance, for instance, to adjust process parameters during production. During heating of $\mathrm{Al}$ alloys, typically a sequence of precipitation and dissolution reactions takes place. One option for kinetic analysis is differential scanning calorimetry (DSC), as dissolution reactions are endothermic, while precipitation reactions are exothermic. A DSC-device always measures

Handling Editor: Megumi Kawasaki.

Address correspondence to E-mail: benjamin.milkereit@uni-rostock.de 
the sum of any heat effect (i.e. any reactions). In terms of the heat flow sum, precipitation and dissolution are opposing processes (exo- versus endothermic), and the DSC signal can potentially be zero even though two or more superimposed reactions are running. This makes the interpretation of heating DSC results on heat treatable $\mathrm{Al}$ alloys complicated [1]. As one major issue, single DSC peaks must not be mixed up with the maximum of the transition rate of the underlying microstructural reaction, for instance a precipitation. Certainly, this is a drawback, as one often aims to learn about certain specific reactions rather than about the sum of reactions. The detailed sequence of alternating exothermic and endothermic reactions depends on the initial conditions; that is, it depends on which phases already are precipitated and how much of the total fraction of alloying element atoms are solved [1]. However, in most cases, the alternating reactions are not well separated but, rather, are superimposed.

Figure 1 shows heating DSC results of alloy EN AW-6082 in initial artificially aged condition T651 at three different heating rates. Starting with the dissolution of the precipitates formed during the

\section{EN AW-6082 T651}

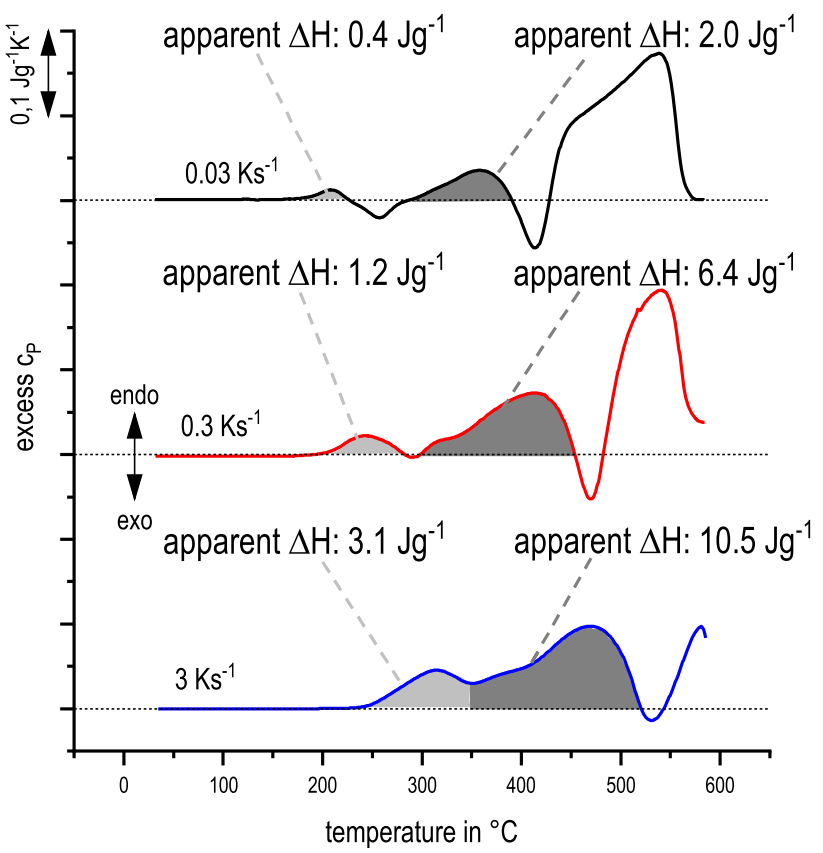

Figure 1 DSC heating curves at the heating rates of $0.03,0.3$, and $3 \mathrm{Ks}^{-1}$ of an alloy: EN AW-6082 T651. The highlighted peak areas seem to correlate to dissolution of the strengthening precipitates without considering overlapping reactions. ageing treatment, a complex alteration of endothermic and exothermic peaks is seen. This indicates a complex superposition of dissolution and precipitation reactions following the precipitation sequence of $\beta-\mathrm{Mg}_{2} \mathrm{Si}$. It is remarkable to note that the peak areas (apparent enthalpy change $\Delta \mathrm{H}$ ) of the first endothermic dissolution peak increase with increasing heating rate. This is not expected, as dissolution relates to diffusion, and thus, should be suppressed with shortening time available. For EN AW-6082, this increase in apparent enthalpy change $\Delta \mathrm{H}$ from 0.03 to $3 \mathrm{Ks}^{-1}$ is found to be by about a factor of 5.5. Similar findings on dynamic changes in DSC heating curves were made on a range of AlMgSi alloys in [1], as well as on two $\mathrm{Al}-\mathrm{Zn}-\mathrm{Mg}(-\mathrm{Cu})$ alloys in [2].

One likely explanation is given by a dynamic change in the superposition of the opposing dissolution and precipitation reactions. Exothermic precipitation reactions are more easily suppressed compared to dissolution reactions-this is predominantly as the diffusion ways are shorter for dissolution reactions compared to precipitation from homogenous solid solutions [3], which leads to a seemingly larger fraction of the dissolution reaction seen in the DSC sum signal at faster heating rates. This general issue was already addressed in previous works [1, 3]. As one major outcome, it is concluded that for age hardening alloys, in most cases, single intensities (peak areas) of DSC peaks may not be interpreted. It directly refers to one single reaction, unfortunately, is exactly the basis of most interpretations of heating DSC signals from $\mathrm{Al}$ alloys, see for instance [4-6]. This is even more doubtful if the DSC peaks are used for the determination of activation energies for the precipitation of specific phases, such as in many works, (e.g. [7-15]), for instance, by applying evaluation methods like the Kissinger method [16].

DSC peak separation can be supported by other in situ methods that allow for the analysis of phase transformations. This has already been shown by comparing DSC and Light Flash Analysis results, as thermal diffusivity also depends on alloy microstructure (e.g. precipitates) [17]. In the first decade of the 2000's high-energy X-ray diffraction (HEXRD) in a synchrotron became another powerful method for studying phase transformation processes in situ [18-20]. Especially the combination of smallangle and wide-angle $\mathrm{X}$-ray scattering experiments enabled to obtain data of the evolution and kinetic 
development of precipitation processes [21-23]. In [24], a methodology of HEXRD data evaluation was established, which allows a transformation rate for precipitation during cooling of $\mathrm{Al}$ alloys to be recalculated. The obtained HEXRD results can be directly compared with the DSC signal, but so far, this was shown only for cooling experiments (at which only precipitation occurs). In this work, we compare HEXRD and DSC data on heating of two Al alloys, assessing precipitation and dissolution of two equilibrium phases, $\beta-\mathrm{Mg}_{2} \mathrm{Si}$ in EN AW-6082 and $\eta-\mathrm{Mg}(\mathrm{Zn}, \mathrm{Cu}, \mathrm{Al})_{2}$ in EN AW-7150.

\section{Materials and methods}

Two aluminium wrought alloys were investigated, namely AlMgSi alloy EN AW-6082 in initial condition T651 (solution treated, quenched, artificially aged, additionally stress relief by stretching) as well as an $\mathrm{AlZnMgCu}$ alloy EN AW-7150 in initial condition T6 (solution treated, quenched, artificially aged). Table 1 gives the mass fractions of alloying elements for the two investigated alloys analysed by optical emission spectroscopy (OES) as well as their nominal composition ranges according to standard EN 573-3.

DSC heating experiments were performed and evaluated as described in [25]. For EN AW-6082, heating was done up to $585^{\circ} \mathrm{C}$, while EN AW-7150 was heated up to $480{ }^{\circ} \mathrm{C}$. For each alloy, at least four to eight individual samples, each in identical initial conditions, were heated with rates of $0.03,0.3$, and $3 \mathrm{Ks}^{-1}$. The slow measurements at $0.03 \mathrm{Ks}^{-1}$ were performed in the Calvet-type heat flow DSC Setaram $\mathrm{S} 121$. The faster heating tests of 0.3 and $3 \mathrm{Ks}^{-1}$ were performed in two power-compensated PerkinElmer Pyris Diamond DSC. Nitrogen was used as purge gas during the DSC experiments. The DSC results are normalized to the unit of the excess specific heat capacity by dividing the measured heat flow by sample mass and scanning rate. In this work, averaged DSC curves are shown like that introduced in [25].

The general experimental setup for the HEXRD experiments is published in detail in [24]. The cylindrical samples $(\varnothing 4 \times 10 \mathrm{~mm})$ were heated at constant rates in a modified dilatometer type Baehr 805 A/D, which is mounted in the DESY synchrotron facility in Hamburg, Germany (Deutsches Elektronen-Synchrotron). The sample chamber of the dilatometer was evacuated after sample mounting and refilled with Ar to a low under-pressure of $-20 \mathrm{kPa}$. The high energy materials science (HEMS) beamline P07 at PETRA III, which provides tunable photon energies in the $30-200 \mathrm{keV}$ range [26], was used. The incident X-ray beam had an energy of $95.68 \mathrm{keV}$, corresponding to a wavelength of $0.012958 \mathrm{~nm}$, and a size of $0.5 \mathrm{~mm} \times 0.5 \mathrm{~mm}$ in this study. The high beam energy allows the beam to penetrate a bulk aluminium sample with a $4 \mathrm{~mm}$ diameter, and the high intensity of a synchrotron source enables a sufficiently high time resolution for fast in situ heating experiments. For each HEXRD heating experiment, individual samples in identical initial conditions as in DSC were taken.

Characteristic Debye-Scherrer diffraction rings (Fig. 2 A) were recorded at discrete time intervals, which depend on the applied heating rate $(\approx 40 \mathrm{~s}$ at $0.03 \mathrm{Ks}^{-1} ; \approx 0.8 \mathrm{~s}$ at $3 \mathrm{Ks}^{-1}$ ). By rotational integration of the diffraction images, diffractograms like that shown in Fig. 2 B were created. One challenge for the further evaluation is to find appropriate diffraction peaks related to one single phase and well separated from other peaks, while also considering the temperature shift related to thermal expansion. The considered peaks within the integrated diffraction pattern were identified using the DIFFRACplus PDFMaint database 15.0.0.0 (Bruker-AXS 1996-2009, [27]). Relevant phases in EN AW-7150 include $\mathrm{S}-\mathrm{Al}_{2} \mathrm{CuMg}$ precipitates and isostructural

Table 1 Mass fractions of alloying elements in the investigated aluminium wrought alloys

\begin{tabular}{lllllllllll}
\hline mass fraction in $\%$ & $\mathrm{Si}$ & $\mathrm{Fe}$ & $\mathrm{Cu}$ & $\mathrm{Mn}$ & $\mathrm{Mg}$ & $\mathrm{Cr}$ & $\mathrm{Zn}$ & $\mathrm{Ti}$ & $\mathrm{Zr}$ \\
\hline EN AW-6082 & OES & 0.83 & 0.38 & 0.06 & 0.48 & 0.92 & 0.03 & 0.01 & 0.02 & - \\
& EN 573-3 & $0.7-1.3$ & $<0.5$ & $<0.1$ & $0.4-1.0$ & $0.6-1.2$ & $<0.25$ & $<0.2$ & $<0.1$ \\
EN AW-7150 & OES & 0.02 & 0.05 & 2.04 & 0.04 & 2.15 & $<0.01$ & 6.33 & 0.01 & 0.12 \\
& EN 573-3 & $<0.12$ & $<0.15$ & $1.9-2.5$ & $<0.1$ & $2.0-2.7$ & $<0.04$ & $5.9-6.9$ & $<0.06$ & $0.08-0.15$ \\
\hline
\end{tabular}



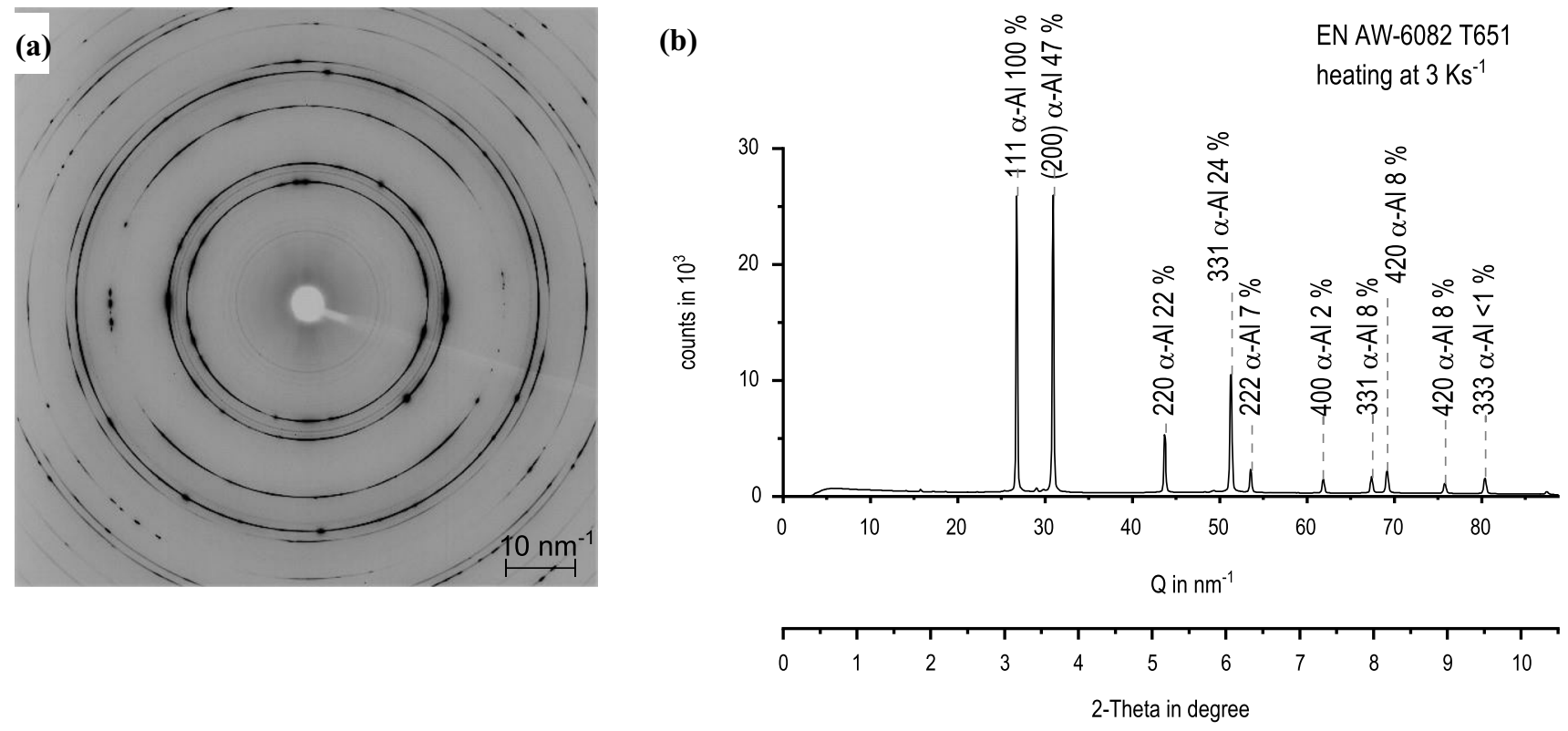

Figure 2 a diffraction pattern at $100{ }^{\circ} \mathrm{C}$ during heating of EN AW-6082 T651 at $3 \mathrm{Ks}^{-1}$, b diffraction-data converted into a diffractogram at $100{ }^{\circ} \mathrm{C}$ during heating of EN AW-6082 $\mathrm{T} 651$ at $3 \mathrm{Ks}^{-1}$, nominal relative peak intensities in \% according to [27].

variants of $\eta-\mathrm{Mg}(\mathrm{Zn}, \mathrm{Cu}, \mathrm{Al})_{2}$ [28]. The characteristic crystal structure features are as follows for $\eta-\mathrm{Mg}(\mathrm{Zn}, \mathrm{Cu}, \mathrm{Al})_{2}$ (hexagonal, $\mathrm{P} 6_{3} / \mathrm{m} \mathrm{m} \mathrm{c}, \mathrm{a}=0.521$ $\mathrm{nm}, \mathrm{c}=0.860 \mathrm{~nm},[29]$ ) and $\mathrm{S}-\mathrm{Al}_{2} \mathrm{CuMg}$ (orthorhombic, ' $\mathrm{C} \mathrm{m} \mathrm{c} \mathrm{m',} \mathrm{a}=0.400 \mathrm{~nm}, \quad \mathrm{~b}=0.923 \mathrm{~nm}$, $c=0.714 \mathrm{~nm},[29])$. In alloy $6082, \beta-\mathrm{Mg}_{2} \mathrm{Si}$ phase (fcc, 'F m -3 m', a $=0.639 \mathrm{~nm}$, [29]) is the relevant equilibrium phase. The crystal structure of these equilibrium precipitates can clearly be distinguished from their precursors $\beta^{\prime}-\mathrm{Al}_{2} \mathrm{MgSi}_{2}$ (hexagonal, $\mathrm{a}=$ $0.705 \mathrm{~nm}, \quad c=0.405 \mathrm{~nm} \quad$ [29]), or $\mathrm{B}^{\prime}-\mathrm{Al}_{4} \mathrm{Mg}_{8} \mathrm{Si}_{7}$ (hexagonal, $a=1.04 \mathrm{~nm}, c=0.405 \mathrm{~nm} \mathrm{[29])} \mathrm{and}$ $\eta^{\prime}$ (hexagonal, $a=0.496 \mathrm{~nm}, c=1.405 \mathrm{~nm}$ [29]), respectively The most intensive rings in Fig. $2 \mathrm{~A}$ belong to the aluminium matrix resulting in the typical fcc diffraction pattern visible in Fig. 2B. The fine-grained $\mathrm{Al}$ matrix (mean grain size $<10 \mu \mathrm{m}$ ) a few larger $\mathrm{Al}$ grains exist (about $100 \mu \mathrm{m}$ ) resulting in additional spots within the rings, as visible in Fig. 2A. Besides the $\mathrm{Al}$ rings, very weak additional rings are visible in Fig. 2A. They can be attributed to precipitates of $\beta-\mathrm{Mg}_{2} \mathrm{Si}$ and its coarser precursors, $\beta^{\prime}$ and $B^{\prime}$. These precipitates are still relatively large because they show clear Bragg peaks and no preferred orientation could be observed in the rings. These precipitates were either not completely dissolved during the solution treatment or formed during the initial artificial ageing of the material. A more detailed part of diffractograms for alloy EN-AW 6082 taken at different temperature is shown in Fig. 3. Selected Al- and $\beta$-diffraction peaks with relative high intensities are indicated and the peak shift related to thermal expansion is clearly visible, e.g. for $111 \alpha-\mathrm{Al}$.

For the example of EN AW-6082 T651, Fig. 4 shows the 111 diffraction peak of the phase $\beta-\mathrm{Mg}_{2} \mathrm{Si}$ as a function of temperature during heating. The evaluated peak at $17.10 \mathrm{~nm}^{-1}$ was chosen because it has a high intensity and there is no overlap with other peaks in this area, so that a reliable evaluation can be guaranteed, for more details see [24]. It can be seen that the phase $\beta-\mathrm{Mg}_{2} \mathrm{Si}$ seems to be present already in the initial state. With increasing temperature, the peak area up to about $300{ }^{\circ} \mathrm{C}$ stays constant and then starts to increase from about $300{ }^{\circ} \mathrm{C}$ up to about $435{ }^{\circ} \mathrm{C}$, i.e. further $\beta-\mathrm{Mg}_{2} \mathrm{Si}$ is precipitated. At higher temperatures, the peak decreases as the $\beta-\mathrm{Mg}_{2} \mathrm{Si}$ phase is partly dissolved. The course of peak areas depending on temperature has been differentiated to calculate a transformation rate (for details, see [24]). Figure $4 \mathrm{~b}$ shows a colour-coded top view of the of evolution of $111 \beta-\mathrm{Mg}_{2} \mathrm{Si}$. Besides the linear thermal expansion, an additional peak shift is visible in the temperature range from about $350{ }^{\circ} \mathrm{C}$ up to about $450{ }^{\circ} \mathrm{C}$. This peak shift can be attributed to an expansion of the $\beta-\mathrm{Mg}_{2} \mathrm{Si}$ lattice due to a change in the chemical composition, which is well known from other alloys [20]. Additionally, in the range from 
Figure 3 Detailed view of four individual diffractograms during the heating of $\mathrm{EN}$ AW-6082 T651 at $0.3 \mathrm{Ks}^{-1}$ at different temperatures showing the shift of the high-intensity peaks, nominal relative peak intensities in \% according to [27].

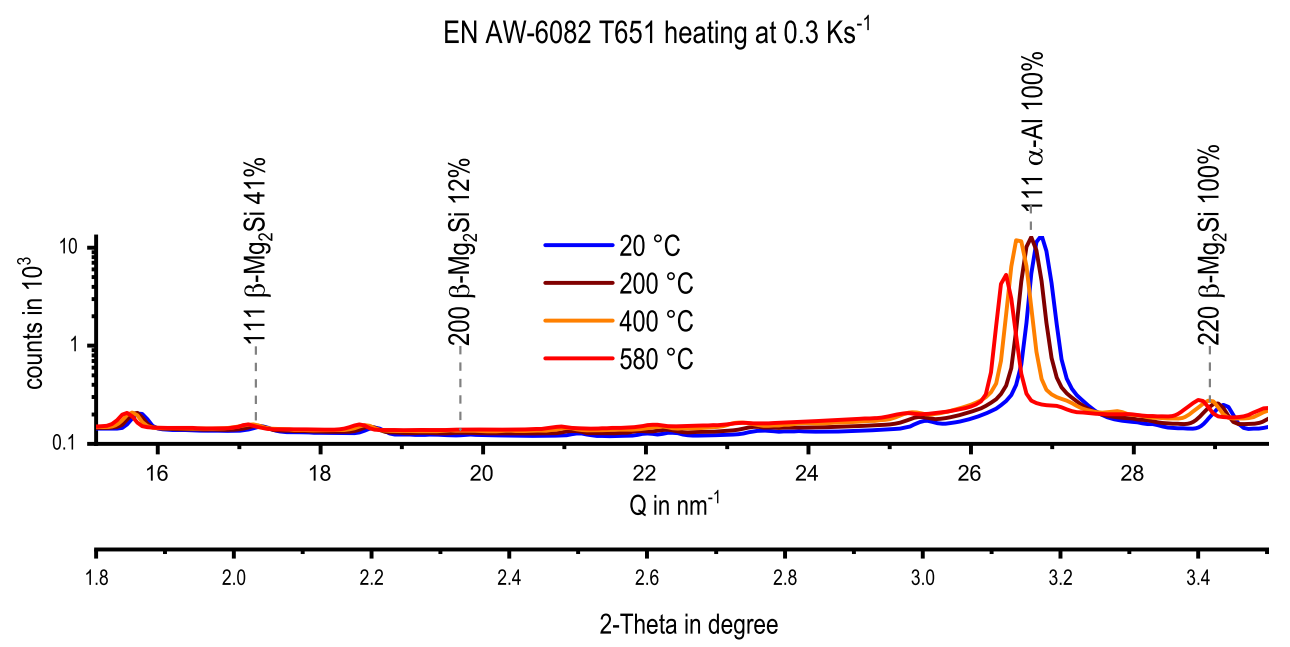

(a) normalised diffraction pattern during heating of EN AW-6082 T651 at $0.3 \mathrm{Ks}^{-1}$ at the $111 \mathrm{Mg}_{2}$ Si-peak

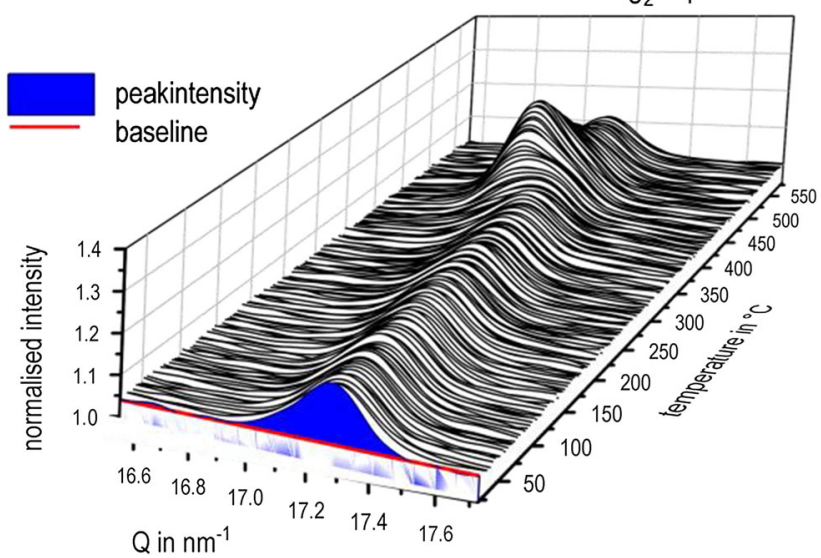

(b) normalised color contour map during heating of EN AW-6082 T651 at $0.3 \mathrm{Ks}^{-1}$ at the $111 \mathrm{Mg}_{2}$ Si-peak

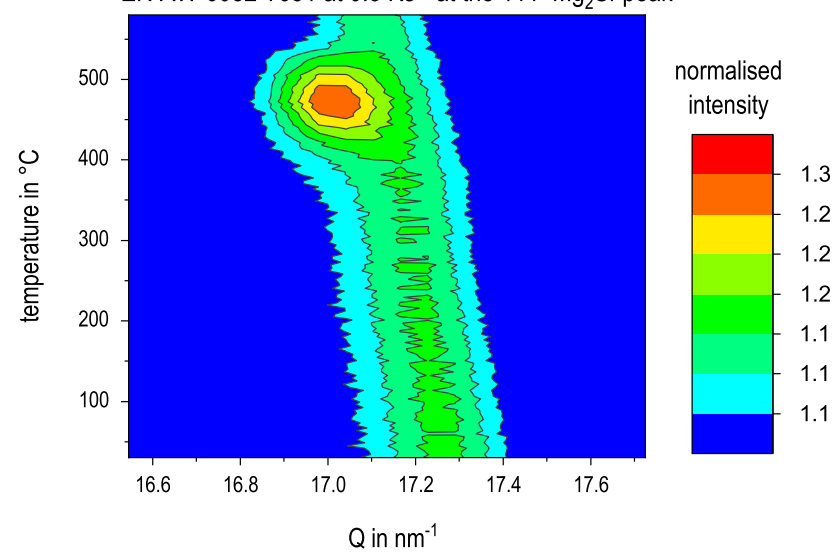

Figure 4 Development of one diffraction peak related to the phase $\beta-\mathrm{Mg}_{2} \mathrm{Si}$ in EN AW-6082 as a function of increasing temperature. a $3 \mathrm{D}$ plot; $\mathbf{b}$ colour-coded top-view.

about $350{ }^{\circ} \mathrm{C}$ up to about $400{ }^{\circ} \mathrm{C}$ a significant peak broadening can be observed which reduces again up to about $450{ }^{\circ} \mathrm{C}$. At the beginning of the precipitation, additional small $\beta-\mathrm{Mg} 2 \mathrm{Si}$ crystallites nucleate. The small size of these nuclei results in the significant peak broadening. Within the course of the precipitation, crystal growth becomes dominating and the peak width reduces again. Besides, healing of crystal defects is an additional reason for the decrease of the peak width.

\section{Results}

The diffraction peak areas (see Fig. 5a, b, c) as well as the phase transformation rates (see Fig. 5d, E, F) for all three heating rates considered are given as a function of temperature for $\beta-\mathrm{Mg}_{2} \mathrm{Si}$ in $\mathrm{EN} \mathrm{AW}-6082$. Starting from room temperature, it can be seen that with increasing temperature, at first, the equilibrium phase $\beta$ is precipitated. After the maximal precipitation transformation rate is reached, with further increase of temperature, a zero crossing can be observed, indicating the beginning of the dissolution of the considered phase. The relevant temperatures, e.g. their transformation rate peak temperatures, are shifted to higher temperatures with increasing heating rate. This is accompanied by a decrease in the intensity of precipitation and dissolution reactions, i.e. the transformed phase fraction is reduced at higher heating rates. For EN AW-6082, it is remarkable that, at a heating rate of $3 \mathrm{Ks}^{-1}$, phase $\beta-\mathrm{Mg}_{2} \mathrm{Si}$ cannot be fully dissolved in the aluminium matrix until $585^{\circ} \mathrm{C}$. This is seen as the HEXRD peak 
Figure 5 a, b, c Peak areas of $111 \beta-\mathrm{Mg}_{2} \mathrm{Si}$ of EN AW6082 T651 during heating at A: $0.03 \mathrm{Ks}^{-1}$; B: $0.3 \mathrm{Ks}^{-1}$; C: $3 \mathrm{~K}^{-1} ; \mathbf{d}, \mathbf{e}, \mathbf{f}$ minus one times 1 st differentiation of the smoothed peak area curve to the process variable

"transformation rate".

EN AW-6082 T651 heating $111 \beta-\mathrm{Mg}_{2}$ Si $17.10 \mathrm{~nm}^{-1}$

(a)

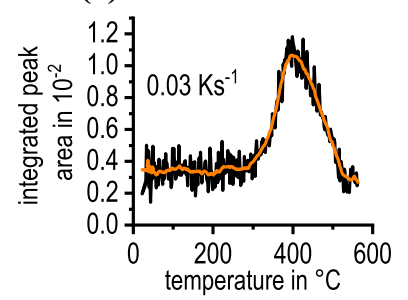

(d)

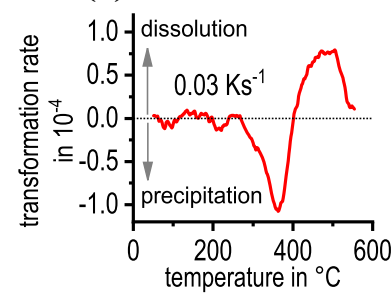

(b)

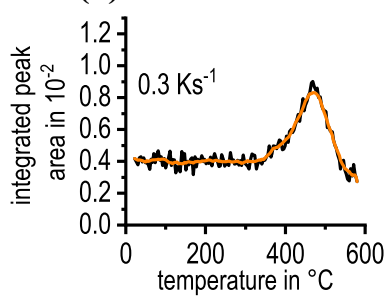

(e)

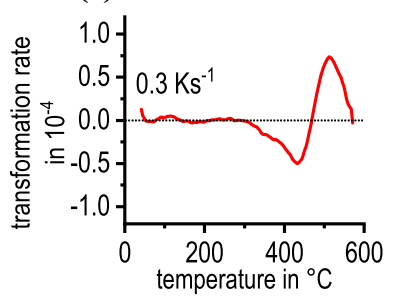

(c)

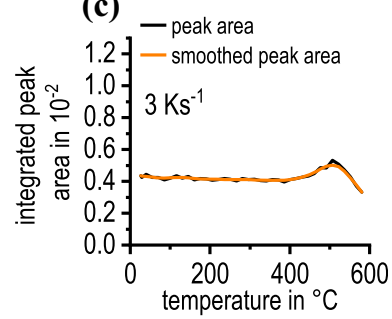

(f)

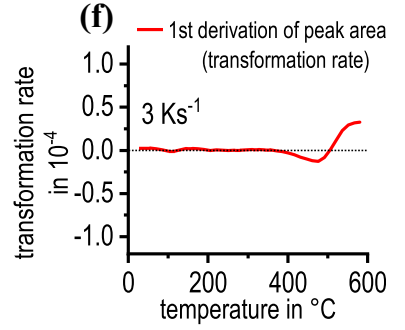

intensity does not drop to the zero level when reaching the maximum temperature $585{ }^{\circ} \mathrm{C}$ during heating.

The integrated 002 diffraction peak areas of the $\eta-\mathrm{Mg}(\mathrm{Zn}, \mathrm{Cu}, \mathrm{Al})_{2}$ phase in EN AW-7150 (see Fig. 6a, $\mathrm{b}, \mathrm{c})$ as well as the corresponding phase transformation rates (see Fig. 6d, e, f) for all three heating rates considered are given as a function of temperature in Fig. 6. Assessing the diffraction HEXRD-peak areas, it can be seen that at room temperature, no equilibrium $\eta-\mathrm{Mg}(\mathrm{Zn}, \mathrm{Cu}, \mathrm{Al})_{2}$ is present. With increasing temperature, $\eta-\mathrm{Mg}(\mathrm{Zn}, \mathrm{Cu}, \mathrm{Al})_{2}$ is precipitated with increasing transformation rate. For a heating rate of

$0.03 \mathrm{Ks}^{-1}$, after reaching the maximum transformation rate at $260{ }^{\circ} \mathrm{C}$, the intensity of precipitation decreases rapidly. The curve is crossing the zero level, indicating the subsequent dissolution of $\eta-\mathrm{Mg}(\mathrm{Zn}, \mathrm{Cu}, \mathrm{Al})_{2}$, which is finished at about $475{ }^{\circ} \mathrm{C}$. The relevant transformation rate peaks are shifted to higher temperatures with increasing heating rate. This is accompanied by a decrease in the intensity of precipitation and dissolution reactions, i.e. the transformed phase fraction is reduced at higher heating rates. The general kinetic behaviour of precipitation and dissolution during heating at various rates of the $\eta-\mathrm{Mg}(\mathrm{Zn}, \mathrm{Cu}, \mathrm{Al})_{2}$ phase in $\mathrm{EN} \mathrm{AW}-7150$

Figure 6 a, b, c Integrated peak areas of $002 \eta$ $\mathrm{Mg}(\mathrm{Zn}, \mathrm{Cu}, \mathrm{Al})_{2}$ of $\mathrm{EN} \mathrm{AW}-$ 7150 T6 during heating at A: $0.03 \mathrm{Ks}^{-1}$; B: $0.3 \mathrm{Ks}^{-1}$; $\mathrm{C}$ : $3 \mathrm{Ks}^{-1} ; \mathbf{d}, \mathbf{e}, \mathbf{f}$ minus one times 1 st derivate of the smoothed integral curve to the process variable "transformation rate".

EN AW-7150 T6 heating 002 ๆ-MgZn $14.64 \mathrm{~nm}^{-1}$

(a)

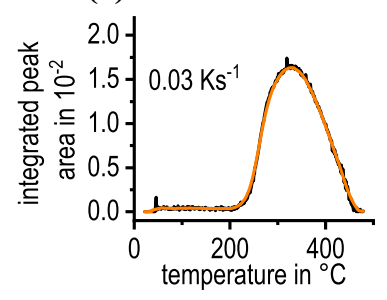

(d)

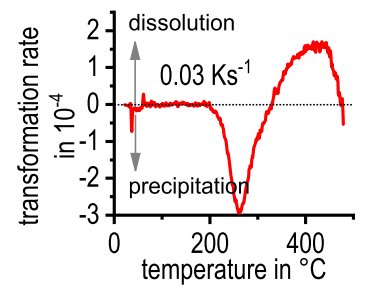

(b)

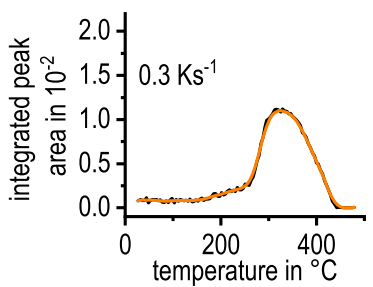

(e)

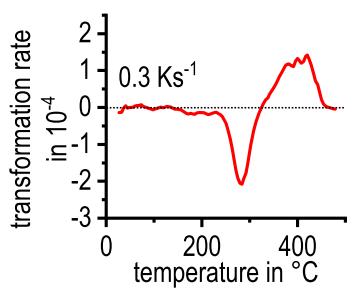

(c)

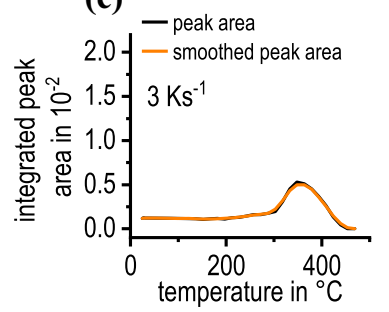

(f)

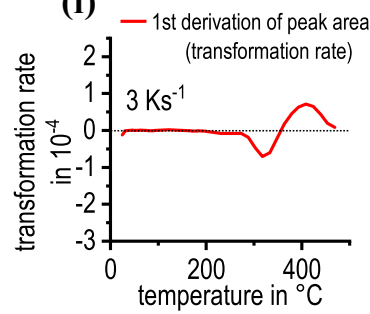


T6 are, thereby, found to be very similar to those of the $\beta-\mathrm{Mg}_{2} \mathrm{Si}$ phase in alloy EN AW-6082 T651. In this work, during heating of EN AW-7150 T6 (within the heating rate spectrum applied), precipitation or dissolution of the $\mathrm{S}-\mathrm{Al}_{2} \mathrm{CuMg}$ phase is not observed by HEXRD.

Exemplarily, Fig. 7 shows the reproducibility of the transformation rate curves for $\eta-\mathrm{Mg}(\mathrm{Zn}, \mathrm{Cu}, \mathrm{Al})_{2}$ in EN AW-7150 generated from the HEXRD signal. Part A of Fig. 7 represents the reproducibility from three individual samples, which is found to be good. In a similar way, Part B of Fig. 7 shows a good agreement evaluating different diffraction peaks of $\eta$ $\mathrm{Mg}(\mathrm{Zn}, \mathrm{Cu}, \mathrm{Al})_{2}$. It can be concluded that the methodology introduced for the cooling experiments [24] can be transferred successfully to the heating experiments.

In Figs. 8 and 9, direct comparisons of DSC and HEXRD data for the $\beta$-phase in EN AW-6082 (A), as well as for the $\eta$-phase in EN AW-7150 (B), are summarized. The black curves show the results of the HEXRD measurements. Each curve is shown with its own zero level (dotted horizontal straight line). A deviation below the respective zero level indicates a precipitation reaction, while a deviation above the zero level indicates a dissolution reaction during heating. The blue curves show the results of the DSC measurements. Also in the DSC measurements, a deviation of the curve above the respective zero level shows that, in sum, a dissolution reaction dominates, while a deviation below the zero level shows domination of precipitation reactions.

The HEXRD results in Fig. 8 show that precipitation of the equilibrium phase $\beta-\mathrm{Mg}_{2} \mathrm{Si}$ in the alloy EN AW-6082 T651 starts at $270{ }^{\circ} \mathrm{C}$ at a heating rate of $0.03 \mathrm{Ks}^{-1}$. The maximum transformation rate of this

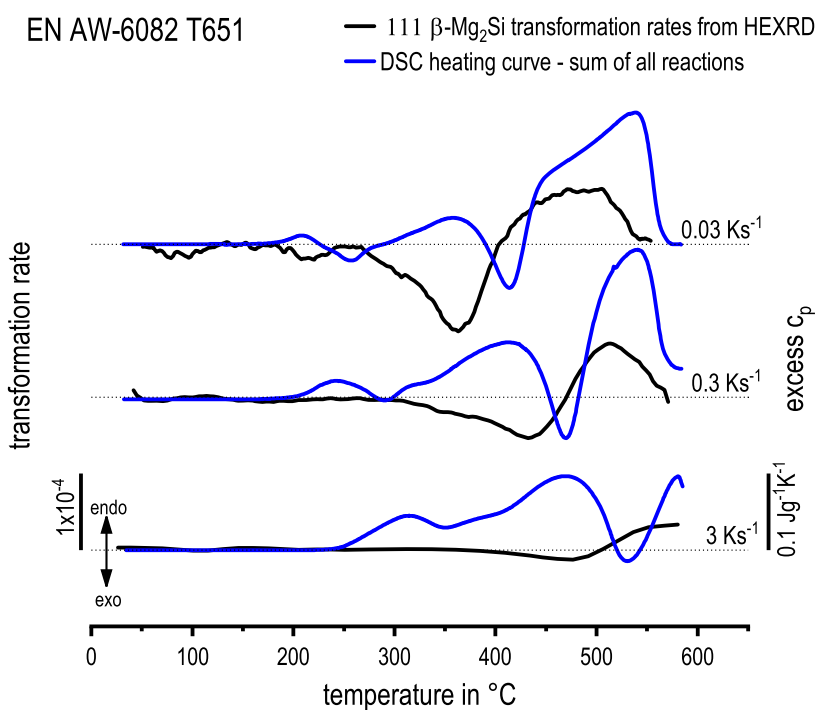

Figure 8 Comparison of HEXRD $\beta-\mathrm{Mg}_{2} \mathrm{Si}$ transformation rates from $111 \beta-\mathrm{Mg}_{2} \mathrm{Si}$ to DSC curves [30] during heating of EN AW$6082 \mathrm{~T} 651$ at different heating rates.

phase is reached at $360{ }^{\circ} \mathrm{C}$. From $400{ }^{\circ} \mathrm{C}$ on, the formed $\beta-\mathrm{Mg}_{2} \mathrm{Si}$ precipitates are dissolved again. The dissolution of the equilibrium phase $\beta-\mathrm{Mg}_{2} \mathrm{Si}$ has stopped at $540{ }^{\circ} \mathrm{C}$ at a heating rate of $0.03 \mathrm{Ks}^{-1}$. The HEXRD results in Fig. 8 further show that the temperature ranges of precipitation and dissolution of the equilibrium phase $\beta-\mathrm{Mg}_{2} \mathrm{Si}$ are shifted to higher temperatures with increasing heating rate. For example, the maximum transformation rate of $\beta-\mathrm{Mg}_{2} \mathrm{Si}$ precipitation is shifted from $360^{\circ} \mathrm{C}$ at $0.03 \mathrm{Ks}^{-1}$ to $435{ }^{\circ} \mathrm{C}$ at $0.3 \mathrm{Ks}^{-1}$, and finally to $475{ }^{\circ} \mathrm{C}$ at $3 \mathrm{Ks}^{-1}$. At the heating rate of $3 \mathrm{Ks}^{-1}$, it is evident that the dissolution of the $\beta-\mathrm{Mg}_{2} \mathrm{Si}$ phase was not completed at $585{ }^{\circ} \mathrm{C}$. Moreover, it can be seen that the areas of the transformation rate peaks in the HEXRD signals decrease with increasing heating rate.

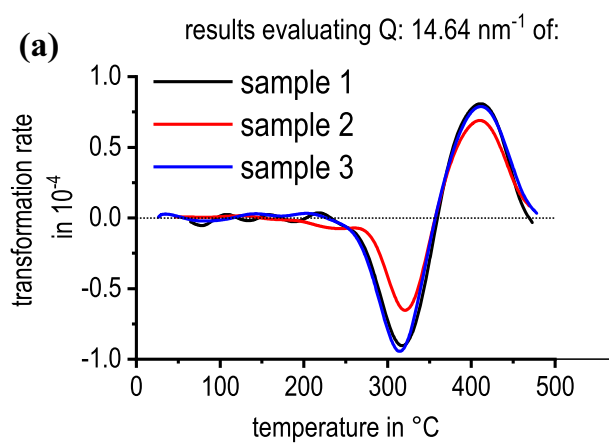

Figure 7 a Comparison of three samples of alloy EN AW-7150 at a heating rate of $3 \mathrm{Ks}^{-1}$ (results evaluating $002 \eta-\mathrm{MgZn}_{2}$ ) and b Comparison of three investigated Bragg peaks of sample 1: 002

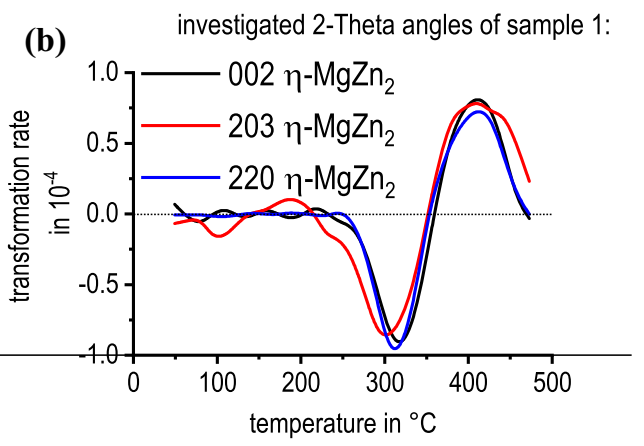

$\eta-\mathrm{MgZn}_{2} ; 203 \eta-\mathrm{MgZn}_{2} ; 220 \eta-\mathrm{MgZn}_{2}$ of alloy EN AW-7150 at a heating rate of $3 \mathrm{Ks}^{-1}$. 


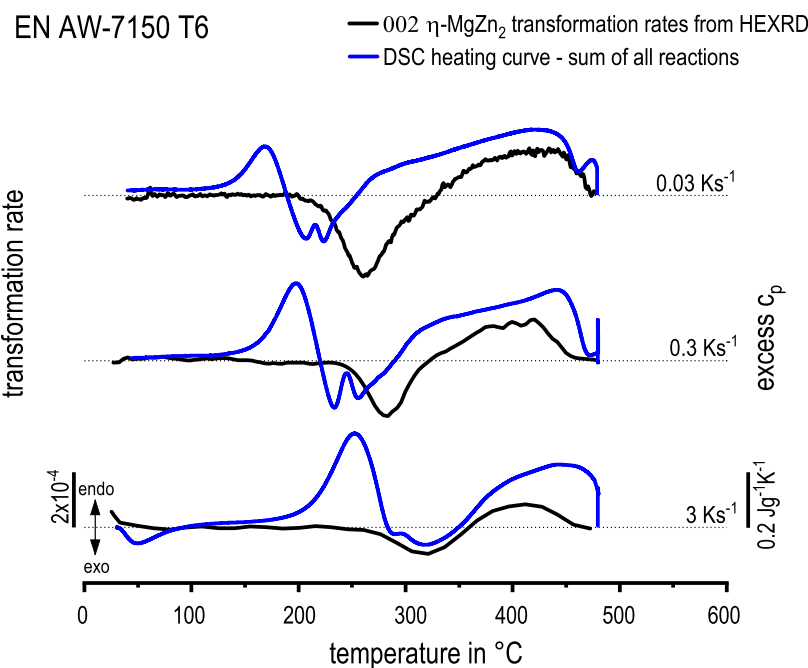

Figure 9 Comparison of HEXRD transformation rates from 002 $\eta-\mathrm{MgZn}_{2}$ to DSC curves during heating of EN AW-7150 T6 at different heating rates.

The DSC measurements of alloy EN AW-6082 T651 also show that the measured peaks are shifted to higher temperatures with increasing heating rate. It turns out, however, that the various reactions overlap severely in this alloy. While the HEXRD results clearly show precipitation of the equilibrium phase $\beta-\mathrm{Mg}_{2} \mathrm{Si}$ in the temperature range of $270-400{ }^{\circ} \mathrm{C}$ at a heating rate of $0.03 \mathrm{Ks}^{-1}$, an endothermic dissolution reaction dominates in DSC measurements in the identical temperature range. This shows that, between 270 and $400{ }^{\circ} \mathrm{C}$, the equilibrium phase $\beta$ $\mathrm{Mg}_{2} \mathrm{Si}$ is precipitated (see HEXRD results), while other phases (likely $\mathrm{Mg}_{2} \mathrm{Si}$ precursor phases $\beta^{\prime}$ and $\left.\beta^{\prime \prime}\right)$ are dissolved at the same time (see DSC results). However, these precursor phases are too small to be detected using HEXRD. The same behaviour can also be observed at higher heating rates of 0.3 and $3 \mathrm{Ks}^{-1}$ for the alloy EN AW-6082 T651. In all recorded heating curves, it can be seen that, in the DSC curves, an endothermic dissolution reaction dominates in the temperature range in which the HEXRD results indicate precipitation of the equilibrium phase $\beta$ $\mathrm{Mg}_{2} \mathrm{Si}$. Coming back to the increase in the DSC peak areas (apparent enthalpies) of the endothermic dissolution peaks at lower temperatures (with increasing heating rate), it can, indeed, be seen from Fig. 8 that this DSC peak area enlargement is related to the more severe suppression of the superimposed precipitation reactions (as postulated in [3]) rather than to an increase of any dissolution reaction.
At higher temperatures between 400 and $540{ }^{\circ} \mathrm{C}$ and a heating rate of $0.03 \mathrm{Ks}^{-1}$, the HEXRD results show that the equilibrium phase $\beta-\mathrm{Mg}_{2} \mathrm{Si}$ is dissolved again. In the DSC measurements, a dominating dissolution reaction is measured up to even higher temperatures in comparison with the HEXRD results. One possible explanation for ongoing dissolution reactions is the dissolution of Mn-containing dispersoids [25] and/or dissolution of excess Si.

The small exothermic precipitation DSC peak between 390 and $430{ }^{\circ} \mathrm{C}$ at $0.03 \mathrm{Ks}^{-1}$ is often interpreted as the precipitation of the equilibrium phase $\beta-\mathrm{Mg}_{2} \mathrm{Si}$ [30]. From the comparison of the available measurements from HEXRD and DSC, it is obvious that this exothermic DSC peak represents only part of the precipitation of equilibrium phase $\beta-\mathrm{Mg}_{2} \mathrm{Si}$.

The HEXRD results in Fig. 9 show that precipitation of the equilibrium phase $\eta-\mathrm{Mg}(\mathrm{Zn}, \mathrm{Cu}, \mathrm{Al})_{2}$ in alloy EN AW-7150 T6 starts at $210{ }^{\circ} \mathrm{C}$ at a heating rate of $0.03 \mathrm{Ks}^{-1}$. The maximum transformation rate is reached at $260^{\circ} \mathrm{C}$. The curve crosses the zero level at $330{ }^{\circ} \mathrm{C}$, which means the previously formed $\eta-\mathrm{Mg}(\mathrm{Zn}, \mathrm{Cu}, \mathrm{Al})_{2}$ precipitates are being dissolved in the aluminium matrix. For the considered heating rate of $0.03 \mathrm{Ks}^{-1}$, dissolution of the equilibrium phase $\eta-\mathrm{Mg}(\mathrm{Zn}, \mathrm{Cu}, \mathrm{Al})_{2}$ is completed at around $475{ }^{\circ} \mathrm{C}$. With increasing heating rate, it can be seen that specific reactions are shifted to higher temperatures. This, for example, holds for the precipitation peak maximum of equilibrium phase $\eta-\mathrm{Mg}(\mathrm{Zn}, \mathrm{Cu}, \mathrm{Al})_{2}$, which was found to be $260{ }^{\circ} \mathrm{C}$ at $0.03 \mathrm{Ks}^{-1}, 280{ }^{\circ} \mathrm{C}$ at $0.3 \mathrm{Ks}^{-1}$, and finally $320^{\circ} \mathrm{C}$ at $3 \mathrm{Ks}^{-1}$. In contrast to $\beta-\mathrm{Mg}_{2} \mathrm{Si}$ in EN AW-6082 (Fig. 8), even at the highest investigated heating rate of $3 \mathrm{Ks}^{-1}$, phase $\eta-\mathrm{Mg}(\mathrm{Zn}, \mathrm{Cu}, \mathrm{Al})_{2}$ can be dissolved completely in the matrix of EN AW-7150 during heating up to $480{ }^{\circ} \mathrm{C}$ solution annealing temperature. As for $\beta-\mathrm{Mg}_{2} \mathrm{Si}$ in EN AW-6082 T651, it can be seen that the intensity of the precipitation peak as well as the following dissolution peak in the HEXRD results decrease with increasing heating rate.

The DSC curve of alloy EN AW-7150 T6 with $0.03 \mathrm{Ks}^{-1}$ shows a first endothermic peak, which shifts from $170{ }^{\circ} \mathrm{C}$ at $0.03 \mathrm{Ks}^{-1}$ to $250{ }^{\circ} \mathrm{C}$ at $3 \mathrm{Ks}^{-1}$. Presumably, GP-zones as well as $\eta^{\prime}$ precipitates are likely being dissolved as part of this dissolution reaction [31, 32]. The peak area of this endothermic peak increases with increasing heating rate. Furthermore, heating leads to a zero level crossing and, subsequently, to an exothermic reaction with a 
double peak at $210{ }^{\circ} \mathrm{C}$ and $220{ }^{\circ} \mathrm{C}$ for $0.03 \mathrm{Ks}^{-1}$. The reason for the double peak nature has extensively been discussed in [32], and probably, the two peaks are related to the direct transformation from still existing $\eta^{\prime}$ particles to $\eta-\mathrm{Mg}(\mathrm{Zn}, \mathrm{Cu}, \mathrm{Al})_{2}$ (called $\eta_{2}$ variant in [32]) and to a direct precipitation of the $\eta-\mathrm{Mg}(\mathrm{Zn}, \mathrm{Cu}, \mathrm{Al})_{2}$ phase from the solid solution $\left(\eta_{1}\right.$ variant [31, 32]). Finally, another broad endothermic reaction follows starting at $250{ }^{\circ} \mathrm{C}$. According to $[31,32]$, this endothermic reaction is associated with the dissolution of $\eta-\mathrm{Mg}(\mathrm{Zn}, \mathrm{Cu}, \mathrm{Al})_{2}$. All endothermic and exothermic reactions shift with increasing heating rate.

In general, results from both techniques, HEXRD and DSC, show significant differences, and it is evident that there is a severe overlap of simultaneously ongoing reactions, like precipitation, direct phase transformations, and dissolution. This is particularly evident in the case of the alloy EN AW-6082. In the temperature region, where HEXRD shows clearly precipitation of $\beta$ in EN AW-6082 (Fig. 8), the DSC signal is still dominated by dissolution of precursor $\beta^{\prime}$, i.e. the common methodology in assignment of individual DSC signals to certain reactions is inappropriate during heating of Al-alloys. Zero crossings between exothermic and endothermic signals cannot be used in general to differentiate certain reactions, nor can heating DSC peaks be assigned to refer to one single reaction.

Instead, Fig. 10 shows schematically, on alloy EN AW-6082, our assumption of how strongly overlapping precipitation and dissolution reactions can result in the obtained DSC curves. The simplified course of $\beta$-precipitation and $\beta$-dissolution with their relevant temperatures has been transferred from HEXRD (Fig. 8). The courses of $\beta^{\prime}$-dissolution and dispersoid-dissolution are also simplified, but their temperature ranges and relative intensities are justified by DSC measurements [1, 25]. The schematic sum of heat flow curves corresponds well with the measured DSC-curves in Fig. 8. All features can be reproduced, especially the seemingly small exothermic reaction around $400{ }^{\circ} \mathrm{C}$. Comparison with HEXRD shows that this seemingly small exothermic DSC reaction obviously results from a superposition of endothermic $\beta^{\prime}$-dissolution and exothermic $\beta$-precipitation. The $\beta$-precipitation starts already at significantly lower temperatures than seemingly indicated by the small exothermic heat flow sum.

It is remarkable that the HEXRD and DSC results of EN AW-7150 for a heating rate of $3 \mathrm{Ks}^{-1}$ show a good agreement above about $280{ }^{\circ} \mathrm{C}$ (Fig. 9). At first sight, this seems to contradict the above superposition assumption, but at second sight, it is confirmed. In this special case of alloy EN AW-7150, initial state $\mathrm{T} 6$, and heating rate $3 \mathrm{Ks}^{-1}$, the endothermic dissolution of GP-zones and $\eta^{\prime}$-precipitates (about 200$280{ }^{\circ} \mathrm{C}$ ) is almost completely separated from the exothermic $\eta$-precipitation (about $280-350{ }^{\circ} \mathrm{C}$ ). The small overlap does not influence the heat flow of $\eta$ precipitation and subsequent $\eta$-dissolution. Thus, DSC and HEXRD results agree in this temperature range. At higher temperatures, one can assume, again, an additional heat flow contribution from dissolution of other phases.
Figure 10 Schematically overlapping of $\beta^{\prime}$-dissolution, $\beta$-precipitation, $\beta$-dissolution, and dispersoid-dissolution (arbitrary heat flow axis), a single reactions, $\mathbf{b}$ sum of single reactions.
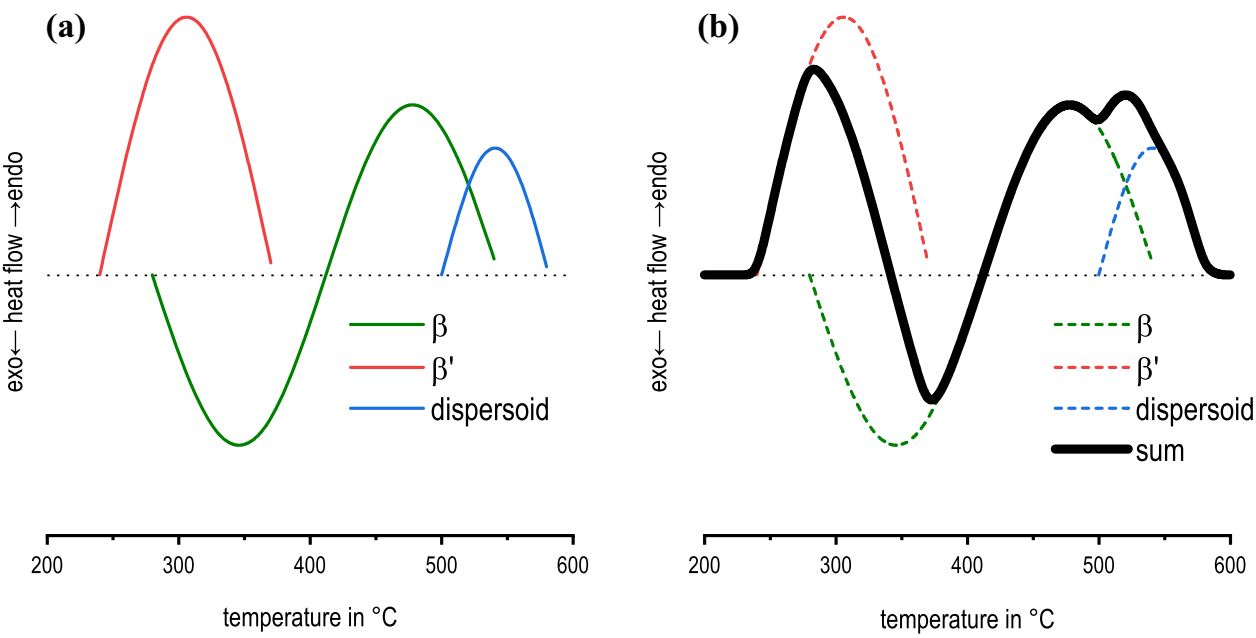


\section{Conclusive summary}

DSC is a powerful method for in situ analysis of precipitation and dissolution reactions in metals over a wide range of heating and cooling rates. However, different simultaneously ongoing reactions cannot be separated easily from each other because the DSC measuring principle detects the heat flow sum of all ongoing reactions at a certain time or temperature. Precise separation of overlapping reactions is difficult, in particular in the case of heating DSC experiments, due to simultaneously running endothermic dissolution reactions and exothermic precipitation reactions. In order to separate the individual reactions from each other, in situ HEXRD was used in this work, as X-Ray diffraction is sensitive regarding individual phases with different crystal structures. Comparing DSC and HEXRD results for the precipitation and subsequent dissolution of $\beta-\mathrm{Mg}_{2} \mathrm{Si}$ in alloy EN AW-6082 as well as $\eta-\mathrm{Mg}(\mathrm{Zn}, \mathrm{Cu}, \mathrm{Al})_{2}$ in alloy EN AW-7150 confirms a severe superposition of different reactions. Common DSC evaluation methods using zero crossing between endothermic and exothermic heat flow or evaluation of DSC single peaks are, therefore, misleading regarding individual reaction start and finish temperatures, as well as regarding reaction intensities or phase transformation rates. However, the combination with other in situ methods like HEXRD can allow appropriate peak separation.

For alloy EN AW-6082 T651, the temperature ranges of precipitation and subsequent dissolution of the equilibrium phase $\beta-\mathrm{Mg}_{2} \mathrm{Si}$ during heating over a wide range of heating rates could be determined by HEXRD. Likewise, for alloy EN AW-7150 T6, the temperature ranges of precipitation and subsequent dissolution of the equilibrium phase $\eta-\mathrm{Mg}(\mathrm{Zn}$, $\mathrm{Cu}, \mathrm{Al})_{2}$ depending on heating rate could be identified. Especially, it is found that $\beta$ - and $\eta$-precipitation starts at significantly lower temperatures than those reported in literature and the apparently corresponding DSC peaks.

Other general DSC results have been confirmed by HEXRD, e.g. peak shift to higher temperatures with increasing heating rate, suppression of peak intensities with increasing heating rate, and stronger suppression of precipitation compared to dissolution reactions with increasing heating rate.

\section{Acknowledgements}

The authors acknowledge the granted measurement time at the high energy materials science beamline P07 at PETRA III, Deutsches Elektronen-Synchrotron, Hamburg, Germany (Proposal I-20170023) and the helpful support of the DESY staff.

\section{Author contribution}

CR, HF, BM, MR, WK, AS, OK designed, performed, evaluated, and discussed the experiments. CR, HF, BM wrote the paper. All authors reviewed the manuscript and agreed to the final version.

\section{Funding}

Open Access funding enabled and organized by Projekt DEAL.

\section{Declarations}

Conflict of Interest The authors declare no conflict of interest.

Open Access This article is licensed under a Creative Commons Attribution 4.0 International License, which permits use, sharing, adaptation, distribution and reproduction in any medium or format, as long as you give appropriate credit to the original author(s) and the source, provide a link to the Creative Commons licence, and indicate if changes were made. The images or other third party material in this article are included in the article's Creative Commons licence, unless indicated otherwise in a credit line to the material. If material is not included in the article's Creative Commons licence and your intended use is not permitted by statutory regulation or exceeds the permitted use, you will need to obtain permission directly from the copyright holder. To view a copy of this licence, visit http://creativecommons.org/licen ses/by/4.0/.

\section{References}

[1] Osten J, Milkereit B, Schick C, Kessler O (2015) Dissolution and precipitation behaviour during continuous heating of 
Al-Mg-Si alloys in a wide range of heating rates. Mater 8(5):2830-2848. https://doi.org/10.3390/ma8052830

[2] Milkereit B, Österreich M, Schuster P, Kirov G, Mukeli E, Kessler O (2018) Dissolution and precipitation behaviour for hot forming of 7021 and 7075 aluminum alloys. Metals 8(7):531. https://doi.org/10.3390/met8070531

[3] Milkereit B, Starink MJ, Rometsch PA, Schick C, Kessler O. 2019 Review of the quench sensitivity of aluminium alloys: analysis of the kinetics and nature of quench-induced precipitation. Materials 12 (24). https://doi.org/10.3390/ma 12244083.

[4] Birol Y (2006) DSC Analysis of the precipitation reactions in the alloy AA6082. J Therm Anal Calorim 83(1):219-222

[5] Birol Y (2008) DSC analysis of the precipitation reaction in AA6005 alloy. J Therm Anal Calorim 93(3):977-981

[6] Dutta I, Allen SM (1991) A calorimetric study of precipitation in commercial aluminium alloy 6061. J Mater Sci Lett 10(6):323-326

[7] Barrena MI, Gómez de Salazar JM, Pascual L, Soria A (2013) Determination of the kinetic parameters in magnesium alloy using TEM and DSC techniques. J Therm Anal Calorim. https://doi.org/10.1007/s10973-012-2791-7

[8] Heugue P, Larouche D, Breton F, Martinez R, Chen XG (2019) Evaluation of the growth kinetics of $\theta^{\prime}$ and $\theta-\mathrm{Al} 2 \mathrm{Cu}$ precipitates in a binary Al-3.5 Wt Pct Cu Alloy. Metallurgical and Materials Transactions A. https://doi.org/10.1007/ s11661-019-05227-8

[9] Khalfallah A, Raho AA, Amzert S, Djemli A. Precipitation kinetics of GP zones, metastable $\eta^{\prime}$ phase and equilibrium $\eta$ phase in $\mathrm{Al}-5.46 \mathrm{wt} . \% \mathrm{Zn}-1.67 \mathrm{wt} . \% \mathrm{Mg}$ alloy. T Nonferr Metal Soc 2019; 29(2): 233-41. https://doi.org/10.1016/S1 003-6326(19)64932-0.

[10] Serradj F, Farh H, Belfarhi B (2019) Study of precipitation hardening in two Al-Mg-Si alloys with and without copper and excess silicon using kissinger and boswell methods. DDF 397:101-110

[11] Belhouchet H, Fatmi M, Sahnoune F, Heraiz M, Saheb N (2018) Dilatometric and DSC study of the kinetics of discontinuous precipitation of $\mathrm{Ag} 2 \mathrm{Al}$ intermetallic in $\mathrm{Al}-10 \%$ Ag Alloy. Met Sci Heat Treat 60(3-4):185-189. https://doi. org/10.1007/s11041-018-0258-6

[12] Hu X, Fang L, Zhou J, Zhang X, Hu H (2017) Characterization and kinetic modeling of secondary phases in squeeze cast Al alloy A380 by DSC thermal analysis. China Foundry 14(2):98-107. https://doi.org/10.1007/s41230-017-6092-4

[13] Hamdi I, Boumerzoug Z (2016) The Natural Aging Effect on the Activation Energy of the Precipitation Processes in the Al-Mg-Si Alloy. KEM 723:27-31

[14] Hamdi I, Boumerzoug Z, Chabane F. STUDY OF PRECIPITATION KINETICS OF AN AL-MG-SI ALLOY
USING DIFFERENTIAL SCANNING CALORIMETRY. Acta Metall. Slovaca 2017;23(2):155. https://doi.org/10.127 76/ams.v23i2.908.

[15] Yin Y, Luo B-H, Bai Z-H, Jing H-B (2019) Quench sensitivity of $\mathrm{Al}-\mathrm{Cu}-\mathrm{Mg}$ alloy thick plate. Rare Met. https://doi. org/10.1007/s12598-018-1196-6

[16] Kissinger HE (1957) Reaction kinetics in differential thermal analysis. Anal Chem 29(11):1702-1706. https://doi.org/10. 1021/ac60131a045

[17] Kemsies RH, Milkereit B, Lindemann A, Schick C, Kessler $\mathrm{O}$ (2020) In situ investigation of precipitation in aluminium alloys via thermal diffusivity from laser flash analysis. J Therm Anal Calor 140:725-733. https://doi.org/10.1007/ s10973-019-08880-8

[18] Poulsen HF, Garbe S, Lorentzen T, Juul Jensen D, Poulsen FW, Andersen NH et al (1997) Applications of high-energy synchrotron radiation for structural studies of polycrystalline materials. J Synchrotron Radiat 4(Pt 3):147-154. https://doi. org/10.1107/S0909049597002021

[19] Liss K-D, Bartels A, Schreyer A, Clemens H (2003) HighEnergy X-rays: a tool for advanced bulk investigations in materials science and physics. Textures and Microstructures 35(3-4):219-252. https://doi.org/10.1080/07303300310001 634952

[20] Liss K-D, Bartels A, Clemens H, Bystrzanowski S, Stark A, Buslaps $\mathrm{T}$ et al (2006) Recrystallization and phase transitions in a $\gamma$-TiAl-based alloy as observed by ex situ and in situ high-energy X-ray diffraction. Acta Mater 54(14):3721-3735. https://doi.org/10.1016/j.actamat.2006.04.004

[21] Andrews RN, Serio J, Muralidharan G, Ilavsky J (2017) An in situ USAXS-SAXS-HEXRD study of precipitate size distribution evolution in a model Ni-based alloy. J Appl Crystallogr 50(3):734-740. https://doi.org/10.1107/S16005767170 06446

[22] Haas S, Andersson J, Fisk M, Park J-S, Lienert U (2018) Correlation of precipitate evolution with Vickers hardness in Haynes ${ }^{\circledR} 282 ®$ superalloy: In-situ high-energy SAXS/ HEXRD investigation. Mater Sci Eng A 711:250-258. https://doi.org/10.1016/j.msea.2017.11.035

[23] Tsao C-S, Huang E-W, Wen M-H, Kuo T-Y, Jeng S-L, Jeng U-S et al (2013) Phase transformation and precipitation of an $\mathrm{Al}-\mathrm{Cu}$ alloy during non-isothermal heating studied by in situ small-angle and wide-angle scattering. J Alloys Compd 579:138-146. https://doi.org/10.1016/j.jallcom.2013.04.201

[24] Rowolt C, Fröck H, Milkereit B, Reich M, Kowalski W, Stark A et al (2020) In-situ analysis of continuous cooling precipitation in Al alloys by wide-angle X-ray scattering. Sci Technol Adv Mater 21(1):205-218. https://doi.org/10.1080/ 14686996.2020.1739554 
[25] Kemsies RH, Milkereit B, Wenner S, Holmestad R, Kessler O (2018) In situ DSC investigation into the kinetics and microstructure of dispersoid formation in Al-Mn-Fe-Si(-Mg) alloys. Mater Des 146:96-107. https://doi.org/10.1016/j.ma tdes.2018.03.007

[26] Schell N, King A, Beckmann F, Fischer T, Müller M, Schreyer A (2013) The High Energy Materials Science Beamline (HEMS) at PETRA III. Mater Sci Forum 772:57-61

[27] Bruker AXS GmbH. DIFFRACplus PDFMaint database 15.0.0.0: Bruker-AXS 1996-2009.

[28] Starink MJ, Milkereit B, Zhang Y, Rometsch PA (2015) Predicting the quench sensitivity of Al-Zn-Mg-Cu alloys: A model for linear cooling and strengthening. Mater Des 88:958-971. https://doi.org/10.1016/j.matdes.2015.09.058

[29] Polmear IJ (2006) Light alloys: From traditional alloys to nanocrystals, 4th edn. Elsevier Butterworth-Heinemann, Amsterdam
[30] Wiechmann P, Panwitt H, Heyer H, Reich M, Sander M, Kessler O (2018) Combined calorimetry thermo-mechanical analysis and tensile test on welded EN AW-6082 Joints. Mater. https://doi.org/10.3390/ma11081396

[31] Adler PN, DeIasi R (1977) Calorimetric studies of 7000 series aluminum alloys: II Comparison of 7075, 7050 and RX720 alloys. Metall Trans A. https://doi.org/10.1007/ BF02667404

[32] Park JK, Ardell AJ (1989) Correlation between microstructure and calorimetric behaviour of aluminum alloy 7075 and $\mathrm{AlZnMg}$ alloys in various tempers. Mater Sci Eng A. https:// doi.org/10.1016/0921-5093(89)90859-9

Publisher's Note Springer Nature remains neutral with regard to jurisdictional claims in published maps and institutional affiliations. 